\title{
Correction to: Electron Cloud Density Generated by Microring-Embedded Nano-Grating System
}

\author{
M. Bunruangses ${ }^{1}$ - P. Youplao ${ }^{2}$ - I. S. Amiri ${ }^{3} \cdot$ N. Pornsuwancharoen ${ }^{2} \cdot$ S. Punthawanunt ${ }^{4}$ - G. Singh ${ }^{5} \cdot$ P. Yupapin $^{3,6}$
}

Published online: 29 July 2020

(C) Springer Science+Business Media, LLC, part of Springer Nature 2020

\section{Correction to: Plasmonics (2020) 15:543-549 https://doi.org/10.1007/s11468-019-01083-9}

The original version of this article unfortunately contained a mistake in the "Acknowledgement" section. As for an important condition required by the first author's affiliation so that the research project can attain the research grant support, the sentence that acknowledges the first author's affiliation must thus be stated appropriately in the article. The corrected 'Acknowledgement' statement is given below.

Acknowledgments The authors would like to acknowledge the research facilities from Ton Duc Thang University, Vietnam, and Rajamangala University of Technology Phra Nakhon, Bangkok 10300, Thailand.

Publisher's Note Springer Nature remains neutral with regard to jurisdictional claims in published maps and institutional affiliations.

The online version of the original article can be found at https://doi.org/ 10.1007/s11468-019-01083-9

\author{
P. Yupapin \\ preecha.yupapin@tdtu.edu.vn \\ M. Bunruangses \\ montree.b@ rmutp.ac.th \\ P. Youplao \\ phichai.yo@rmuti.ac.th \\ I. S. Amiri \\ irajsadeghamiri@tdtu.edu.vn \\ N. Pornsuwancharoen \\ nithiroth.po@rmuti.ac.th \\ S. Punthawanunt \\ suphanchai.pun@kbu.ac.th \\ G. Singh \\ gsingh.ece@mnit.ac.in
}

1 Department of Computer Engineering, Faculty of Industrial Education, Rajamangala University of Technology Phra Nakhon, Bangkok 10300, Thailand

2 Department of Electrical Engineering, Faculty of Industry and Technology, Rajamangala University of Technology Isan, Sakon Nakhon Campus, Sakon Nakhon 47160, Thailand

3 Computational Optics Research Group, Advanced Institute of Materials Science, Ton Duc Thang University, District 7, Ho Chi Minh City, Vietnam

4 Multidisciplinary Research Center, Faculty of Science and Technology, Kasem Bundit University, Bangkok 10250, Thailand

5 Department of ECE, Malaviya National Institute of Technology Jaipur (MNIT), Jaipur, India

6 Faculty of Applied Sciences, Ton Duc Thang University, District 7, Ho Chi Minh City, Vietnam 